\title{
Perancangan Fasilitas Kerja di Warehouse dengan Metode Antropometri
}

\author{
Feraldi Akbar Destian*, Eri Achiraeniwati \\ Prodi Teknik Industri, Fakultas Teknik, Universitas Islam Bandung,
} Indonesia.

*feraldiakbardestian@gmail.com, eri_ach@yahoo.co.id

\begin{abstract}
PT X is a manufacturing company engaged in the garment industry. Manual handling work with an average operator load in one arrival of 1 car moves the product 36 times, carried out by 3 operators. There are problems experienced by operators who complain of pain in several parts of the body, namely the upper back, lower back and feeling sore in some parts of the body. Therefore, the purpose of this research is to design work facilities using anthropometric methods in order to minimize the work risks experienced by bal-transfer workers. The method used to measure work risk is the Ovako Working Analysis System with the ErgoFellow Software tool and to find out operator complaints using the Nordic Body Map questionnaire. Through the questionnaire, it can be seen that the pain experienced by the operator in the shoulder, lower back and upper back and the average risk measurement results are at code 4 level, which means that repairs are needed as soon as possible. Recommendations for designing work facilities are hand lifts based on the dimensions of the worker's body, dimensions of product bales, and available facilities. This hand lift is divided into three parts, namely the part where the load is stored, the control, and the support and hydraulics. The hand lift function is useful for moving product bales, either raising or lowering them. The results of the simulation carried out after the design of the hand lift shows a decrease in the level of risk, when the operator moves the product bales at the risk level at code 1, which means that corrective action is not required.
\end{abstract}

Keywords: Manual Handling, Ovako Working Analysis System, Anthropometry

Abstrak. PT X merupakan suatu perusahaan manufaktur yang bergerak pada bidang industri garmen. Pekerjaan manual handling dengan rata-rata beban operator dalam sekali kedatangan 1 mobil memindahkan produk sebanyak 36 kali pemindahan yang dilakukan oleh 3 operator. Terdapat masalah yang dialami operator yang mengeluhkan sakit pada beberapa bagian tubuh yaitu punggung atas, punggung bawah dan merasa pegal pada beberapa bagian tubuh. Oleh karena itu, tujuan dari penelitian ini adalah untuk merancang fasilitas kerja dengan metode antropometri agar dapat meminimasi risiko kerja yang dialami oleh pekerja pemindahan bal. Metode yang digunakan untuk mengukur risiko kerja adalah Ovako Working Analysis System dengan tool Software ErgoFellow dan untuk mengetahui keluhan operator menggunakan kuesioner Nordic Body Map. Melalui kuesioner dapat diketahui keluhan rasa sakit yang dialami oleh operator pada bahu, punggung bawah dan punggung atas dan hasil pengukuran risiko rata-rata berada pada level kode 4 yang artinya perbaikan diperlukan secepat mungkin. Rekomendasi perancangan fasilitas kerja yaitu hand lift berdasarkan dimensi tubuh pekerja, dimensi bal produk, dan fasilitas yang tersedia. Hand lift ini terbagi menjadi tiga bagian yaitu bagian tempat menyimpan beban, kontrol, serta penyangga dan hidraulik. Fungsi hand lift yaitu berguna untuk memindahkan bal produk, baik menaikkan atau menurunkan. Hasil simulasi yang dilakukan setelah dilakukan perancangan hand lift menunjukkan penurunan level risiko, ketika operator memindahkan bal produk level risiko pada kode 1 yang artinya tindakan perbaikan tidak diperlukan.

Kata Kunci: Manual Handling, Ovako Working Analysis System, Antropometri 


\section{A. Pendahuluan}

Menurut Purnomo Manual Material Handling (MMH) merupakan aktivitas sehari-hari yang dilakukan oleh manusia, meliputi proses mengangkat, menarik, mendorong, menangani, memanipulasi, dan kegiatan penanganan material tanpa bantuan mekanik. Kegiatan manual handling sebagian besar terjadi di bagian warehouse dan pengangkutan barang, namun lebih dominan di bagian warehouse (1). Fasilitas kerja menurut Dahlius dan Ibrahim adalah fasilitas penunjang kegiatan perusahaan dalam bentuk fisik, digunakan untuk aktivitas perusahaan, mempunyai masa pakai yang relatif konstan, dan berguna untuk masa yang akan datang (2).

PT X merupakan suatu perusahaan manufaktur yang bergerak pada bidang industri garmen. Pekerjaan manual handling sampai saat ini masih terjadi di bagian warehouse PT X. Produk datang ke warehouse rata-rata 2 mobil atau 72 bal kaos kaki dan inner fashion/hari. Rata-rata beban operator dalam sekali kedatangan 1 mobil memindahkan produk sebanyak 36 kali pemindahan dengan berat beban lebih dari $20 \mathrm{Kg}$ dalam kurun waktu 1 jam yang dilakukan oleh 3 operator.

Aktivitas pemindahan dilakukan dengan cara di panggul, dimana bal disimpan bertumpu pada satu bahu, satu tangan memegang bal, dan tubuh menjaga keseimbangan dalam menaikkan serta menurunkan bal menggunakan tangga. Fasilitas yang tersedia untuk operator dalam memindahkan produk menggunakan alat bantu berupa tangga kecil membantu ketika menaikkan produk ke rak dan tangga besar digunakan untuk membantu operator dalam menaikkan produk ke rak tingkat 2 dan tingkat 3.

Berdasarkan data yang ada setiap operator melakukan penataan dan penurunan sebanyak 36 bal. Pekerjaan tersebut akan berisiko menimbulkan kecelakaan kerja dan keluhan sakit pada beberapa bagian tubuh ketika memindahkan bal. Berdasarkan (NIOSH, 1994) untuk standar rekomendasi beban angkat maksimum yang dapat diangkat oleh orang Indonesia dewasa yaitu $20 \mathrm{~kg}$ selama periode waktu kerja 8 jam/hari.

Cara pengangkatan menurut Kementerian Tenaga Kerja tidak boleh bertumpukan pada bahu, pengangkatan dilakukan di depan badan dengan beban $16 \mathrm{~kg}$ untuk jarak beban dengan tubuh maksimal $30 \mathrm{~cm}$ dan beban $5 \mathrm{~kg}$ untuk jarak beban dengan tubuh $60 \mathrm{~cm}$ (3). Beban berat antara 16-55 kg untuk pengangkatannya disarankan HSE menggunakan alat bantu dan atau mengangkat beban secara tim (4). Berdasarkan rujukan NIOS tersebut, maka diperlukan perbaikan terhadap cara kerja manual dengan cara menambahkan alat bantu (5). Hasil penelitian pendahuluan diperoleh informasi mengenai keluhan operator saat bekerja berupa sakit pada punggung atas, punggung bawah dan merasa pegal pada beberapa bagian tubuh.

Berdasarkan latar belakang yang telah diuraikan, maka perumusan masalah dalam penelitian ini sebagai berikut:

1. Bagaimana keluhan operator pemindahan produk berdasarkan Nordic Body Map?

2. Bagaimana risiko kerja pada opertor pemindahan produk yang didapatkan dengan metode Ovako Working Analysis System (OWAS) tool Software ErgoFellow?

3. Bagaimana perancangan fasilitas warehouse yang ergonomis untuk mengurangi risiko kerja pada operator?

4. Bagaimana perbandingan besar risiko kerja sebelum dan setelah perancangan dilakukan?

Selanjutnya, tujuan dalam penelitian ini diuraikan dalam pokok-pokok sbb.

1. Mengetahui keluhan operator pemindahan produk berdasarkan Nordic Body Map.

2. Mengetahui risiko kerja saat ini pada operator pemindahan produk menggunakan metode Ovako Working Analysis System (OWAS) tool Software ErgoFellow.

3. Membuat rancangan fasilitas warehouse untuk mengurangi risiko kerja pada operator.

4. Mengetahui perbandingan besar risiko kerja sebelum dan setelah dilakukannya perancangan fasilitas. 


\section{B. Metodologi Penelitian}

Penelitian menggunakan Kuesioner Nordic Body Map dan Metode Ovako Working Analysis System tool Software ErgoFellow. Kuesioner Nordic Body Map digunakan untuk menemukan keluhan pada peta tubuh manusia dalam bentuk beberapa jenis keluhan. Informasi akan didapatkan untuk tubuh mana yang mengalami ketidaknyamanan, dan derajat keluhannya berkisar dari bebas penyakit, sakit ringan, sakit, dan sakit berat. Hasil NBM dapat digunakan untuk memperkirakan kelompok dan jenis, kelelahan dan nyeri yang dialami pekerja saat melihat dan menganalisis peta tubuh yang diperoleh dengan mengisi kuesioner NBM (mulai dari ketidaknyamanan hingga nyeri hebat). Kuesioner NBM sisebarkan pada 3 operator manual handling.

Menilai level risiko kerja pada operator manual handling dengan menggunakan metode Ovako Working Analysis System (OWAS) tool Software ErgoFellow.Penilaian dilakukan pada operator dalam kegiatan mengangkat bal produk, membawa/memindahkan bal produk, menyimpan bal produk ke pallet, menaiki tangga, dan menyimpan bal produk ke rak.

Antropometri adalah analisis kelompok pengguna berdasarkan karakteristik ukuran tubuh yang diukur. Secara umum, populasi adalah sekelompok orang yang terbiasa merancang produk untuk dijual berdasarkan sumber data yang jelas. Pengukuran data antropometri dilakukan untuk kebutuhan perancangan fasilitas kerja.

Tahapan penelitian yang dilakukan adalah sebagai berikut:

1. Studi pendahuluan dan studi pustka.

2. Perumusan masalah.

3. Penetapan tujuan dan batasan masalah.

4. Pengumpulan data terbagi menjadi dua yaitu untuk keluhan operator (penyebaran kuesioner Nordic Body Map) dan kebutuhan pengolahan data penentuan level risiko (berat produk,aktivitas kerja sert posisi kerja).

5. Pengolahan data terbagi menjadi dua yaitu untuk keluhan operator (rekapitulasi keluhan) dan level risiko (penentuan level risiko dan rekapitulasi final skor Ovako Working Analysis System).

6. Analisis keluhan pekerja dan hasil perhitungan OWAS.

7. Perancangan fasilitas kerja dan simulasi.

8. Menghitung level risiko rancangan.

9. Kesimpulan dan saran. 


\section{Hasil Penelitian dan Pembahasan}

\section{Rekapitulasi Keluhan Berdasarkan Kuesioner NBM}

Rekapitulasi kuesioner Nordic Body Map meliputi data keluhan dan data tingkat keluhan operator pemindahan di warehouse ditunjukkan pada Tabel 1.

Tabel 1. Rekapitulasi kuesioner Nordic Body Map

\begin{tabular}{|c|c|c|c|c|c|}
\hline Operator & $\begin{array}{c}\text { Dalam } 12 \text { bulan terakhir } \\
\text { memiliki masalah } \\
\text { bagian tubuh }\end{array}$ & $\begin{array}{c}\text { Selama } 12 \text { bulan } \\
\text { terakhir } \\
\text { terhalang } \\
\text { menjalankan } \\
\text { aktivitas normal }\end{array}$ & $\begin{array}{c}\text { Dalam 7 } \\
\text { hari terakhir } \\
\text { memiliki } \\
\text { rasa nyeri }\end{array}$ & $\begin{array}{c}\text { Penilaian } \\
\text { rasa } \\
\text { sakit }\end{array}$ & $\begin{array}{c}\text { Pernah } \\
\text { menemui } \\
\text { terapis atau } \\
\text { dokter untuk } \\
\text { mengobati } \\
\text { sakit pada } \\
\text { bagian tubuh }\end{array}$ \\
\hline \multirow{4}{*}{1} & Leher & Ya & Ya & 3 & Tidak pernah \\
\cline { 2 - 7 } & Punggung Bawah & Ya & Ya & 6 & Tidak pernah \\
\cline { 2 - 7 } & $\begin{array}{c}\text { Pergelangan tangan } \\
\text { (kanan \& kiri) }\end{array}$ & $\begin{array}{c}\text { Ya, pada bahu } \\
\text { kanan }\end{array}$ & Ya & 6 & Tidak pernah \\
\hline \multirow{4}{*}{2} & Leher & Ya & Ya & 6 & Tidak pernah \\
\cline { 2 - 7 } & Punggung Bawah & Ya & Ya & 5 & Ya \\
\cline { 2 - 7 } & Bahu & $\begin{array}{c}\text { Ya, pada bahu } \\
\text { kiri }\end{array}$ & Ya & 7 & Ya \\
\cline { 2 - 7 } & Punggung Atas & Ya & Ya & 9 & Ya \\
\hline \multirow{2}{*}{3} & Punggung Bawah & Ya & Ya & 7 & Tidak pernah \\
\cline { 2 - 7 } & Bahu & $\begin{array}{c}\text { Ya, pada bahu } \\
\text { kanan }\end{array}$ & Ya & 4 & Tidak pernah \\
\hline
\end{tabular}

Dari Tabel 1 rekapitulasi kuesioner NBM menunjukkan rekapan hasil kuesioner yang telah diberikan pada operator pemindahan. Keluhan pada leher, bahu, punggung bawah, pergelangan tangan dan punggung atas dirasakan operator dengan nilai rasa sakit yang berbeda-beda. Nilai rasa sakit terbesar terdapat pada punggung atas dengan nilai rasa sakit 9 pada operator 2, punggung bawah dengan penilaian rasa sakit 7 pada operator 3, pergerangan tangan dengan nilai rasa sakit 6 pada operator 1, dan bahu dengan nilai rasa sakit 7 pada operator 2 .

\section{Rekapitulasi Level Risiko Kerja Operator Pemindahan Bal Produk}

Penentuan level risiko kerja operator pemindahan bal produk dilakukan menggunakan Metode Ovako Working Analysis System (OWAS) tool Software ErgoFellow pada aktivitas mengangkat bal produk, membawa/memindahkan, menyimpan bal produk ke pallet, menaiki tangga, dan menyimpan bal produk ke rak. Berikut ini rekapitulasi level risiko seluruh operator pemindahan bal produk terdapat pada Tabel 2. 
Tabel 2. Rekapitulasi Level Risiko Kerja Operator Pemindahan Bal Produk

\begin{tabular}{|c|c|c|c|}
\hline Operator & Kegiatan & Level & Keterangan \\
\hline \multirow{5}{*}{1} & Mengangkat bal produk & 3 & Tindakan perbaikan diperlukan segera \\
\hline & $\begin{array}{l}\text { Membawa/memindahkan bal } \\
\text { produk }\end{array}$ & 2 & $\begin{array}{l}\text { Tindakan perbaikan diperlukan di masa } \\
\text { datang }\end{array}$ \\
\hline & $\begin{array}{l}\text { Menyimpan bal produk ke } \\
\text { palllet }\end{array}$ & 4 & $\begin{array}{l}\text { Tindakan perbaikan diperlukan secepat } \\
\text { mungkin }\end{array}$ \\
\hline & Menaiki tangga & 4 & $\begin{array}{l}\text { Tindakan perbaikan diperlukan secepat } \\
\text { mungkin }\end{array}$ \\
\hline & Menyimpan bal produk ke rak & 1 & Tindakan perbaikan tidak diperlukan \\
\hline \multirow{5}{*}{2} & Mengangkat bal produk & 4 & $\begin{array}{l}\text { Tindakan perbaikan diperlukan secepat } \\
\text { mungkin }\end{array}$ \\
\hline & $\begin{array}{l}\text { Membawa/memindahkan bal } \\
\text { produk }\end{array}$ & 1 & Tindakan perbaikan tidak diperlukan \\
\hline & $\begin{array}{l}\text { Menyimpan bal produk ke } \\
\text { pallet }\end{array}$ & 4 & $\begin{array}{l}\text { Tindakan perbaikan diperlukan secepat } \\
\text { mungkin }\end{array}$ \\
\hline & Menaiki tangga & 4 & $\begin{array}{l}\text { Tindakan perbaikan diperlukan secepat } \\
\text { mungkin }\end{array}$ \\
\hline & Menyimpan bal produk ke rak & 4 & $\begin{array}{l}\text { Tindakan perbaikan diperlukan secepat } \\
\text { mungkin }\end{array}$ \\
\hline \multirow{5}{*}{3} & Mengangkat bal produk & 4 & $\begin{array}{l}\text { Tindakan perbaikan diperlukan secepat } \\
\text { mungkin }\end{array}$ \\
\hline & $\begin{array}{l}\text { Membawa/memindahkan bal } \\
\text { produk }\end{array}$ & 2 & $\begin{array}{l}\text { Tindakan perbaikan diperlukan di masa } \\
\text { dating }\end{array}$ \\
\hline & $\begin{array}{l}\text { Menyimpan bal produk ke } \\
\text { pallet }\end{array}$ & 4 & $\begin{array}{l}\text { Tindakan perbaikan diperlukan secepat } \\
\text { mungkin }\end{array}$ \\
\hline & Menaiki tangga & 4 & $\begin{array}{l}\text { Tindakan perbaikan diperlukan secepat } \\
\text { mungkin }\end{array}$ \\
\hline & Menyimpan bal produk ke rak & 4 & $\begin{array}{l}\text { Tindakan perbaikan diperlukan secepat } \\
\text { mungkin }\end{array}$ \\
\hline
\end{tabular}

Level risiko kerja operator rata-rata berada pada level risiko kode 4 yang artinya tindakan perbaikan diperlukan secepat mungkin. Level risiko tinggi dipengaruhi oleh postur dan kondisi operator ketika melakukan aktivitas manual handling, posisi kedua tangan, posisi kaki, dan beban yang di terima operator manual handling.

\section{Perancangan Fasilitas}

Perancangan hand lift dilakukan berdasarkan hasil penilaian keluhan pekerja dengan menggunakan Nordic Boy Map dan hasil penilaian risiko kerja dengan menggunakan metode Ovako Working Analysis System tool Software ErgoFellow. Hasil penilaian risiko kerja menunjukkan bahwa risiko kerja yang dialami oleh pekerja pada saat melakukan aktivitas manual handling di warehouse memiliki level risiko yang tinggi dengan kode mencapai 4. Oleh karena itu, rekomendasi perbaikan yang akan dilakukan untuk meminimasi risiko kerja yang dialami operator adalah melakukan perancangan hand lift.

Dimensi yang digunakan untuk perancangan hand lift sebagai berikut:

1. Lebar Telapak Tangan (LT) digunakan untuk menentukan ukuran gengaman kontrol pada Hand Lift.

2. Tinggi Pinggang (TP) digunakan untuk menentukan tinggi meja kontrol.

3. Panjang Rentang Siku (RS) digunakan untuk menentukan jarak antara kontrol paling kanan (penggerak Hand Lift) dan paling kiri (penggerak hidraulik).

4. Lebar bal produk digunakan untuk menentukan lebar tempat menyimpan beban/produk.

5. Panjang bal produk digunakan untuk menentukan panjang tempat penyimpanan beban/produk.

6. Tinggi bal produk digunakan untuk menentukan tinggi tenyangga beban/ produk.

7. Tinggi rak digunakan untuk menentukan tinggi tiang penyangga dan tinggi hidraulik. 
8. Lebar tiang penyangga digunakan untuk menentukan lebar pembatas.

9. Panjang dudukan hidraulik digunakan untuk menentukan panjang pembatas.

10. Lebar meja kontrol digunakan untuk menentukan lebar alas bagian kontrol.

Penentuan ukuran tubuh menggunakan pendekan Antropometri dengan menggunakan dimensi tubuh Lebar Telapak Tangan (LT),Tinggi Pinggang (TP), dan Rentang Siku (RS). Penentuan sampel dilakukan untuk menentukan jumlah sampel dari populasi yang ada untuk keperluan pengukuran dimensi tubuh. Jumlah populasi yang didapatkan adalah sejumlah 154 orang, berasal dari pekerja manual handling warehouse, manual handling di bagian produksi, mahasiswa angkatan 2016 dan 2017 berdasarkan jenis kelamin yaitu laki-laki dan rata-rata dimensi tubuh yang serupa. Diketahui jumlah sampel yaitu berjumlah 112 orang, penentuan sampel menurut Taro Yamane (6).

Tabel 3. Rekapitulasi ukuran rancangan hand lift

\begin{tabular}{|c|c|c|c|c|c|c|c|}
\hline No & Dimensi Fasilitas Kerja & $\begin{array}{c}\text { Dimensi } \\
\text { Tubuh }\end{array}$ & $\begin{array}{c}\text { Persentil } \\
\text { yang } \\
\text { digunakan } \\
\end{array}$ & $\begin{array}{c}\text { Alasan Penggunaan } \\
\text { Persentil }\end{array}$ & $\begin{array}{c}\text { Toleransi } \\
(\mathrm{cm})\end{array}$ & Alasan Toleransi & $\begin{array}{l}\text { Ukuran Akhir } \\
\qquad(\mathrm{cm})\end{array}$ \\
\hline 1 & $\begin{array}{c}\text { Ukuran gengaman kontrol } \\
\text { pada Hand Lift }\end{array}$ & LTT & P5 & $\begin{array}{l}\text { Agar mudah digengam } \\
\text { oleh operator yang lebar } \\
\text { telapak tangannya kecil }\end{array}$ & 0,5 & $\begin{array}{c}\text { Pemberian } \\
\text { karet/plastik pada } \\
\text { kontrol genggaman }\end{array}$ & 14 \\
\hline 2 & Tinggi meja kontrol & $\mathrm{TP}$ & P50 & $\begin{array}{c}\text { Agar tinggi meja tidak } \\
\text { membuat operator yang } \\
\text { berbadan pendek jingjit dan } \\
\text { operator berbadan tinggi } \\
\text { menunduk }\end{array}$ & - & - & 111 \\
\hline 3 & $\begin{array}{c}\text { Jarak antara kontrol paling } \\
\text { kanan (penggerak Hand } \\
\text { Lift) dan paling kiri } \\
\text { (penggerak Hidraulik) }\end{array}$ & RS & P50 & \begin{tabular}{|c|} 
Agar operator mudah \\
menjangkau dan \\
menggunakan baik kontrol \\
penggerak hand lift dan \\
penggerak hidraulik
\end{tabular} & - & - & 60 \\
\hline 4 & $\begin{array}{c}\text { Lebar tempat menyimpan } \\
\text { beban/produk }\end{array}$ & - & - & - & 24 & \begin{tabular}{|c|} 
Agar dapat \\
menampung \\
beban/produk dengan \\
ukuran melebihi \\
beban/produk terbesar \\
\end{tabular} & 130 \\
\hline 5 & $\begin{array}{c}\text { Panjang tempat } \\
\text { penyimpanan beban/produk }\end{array}$ & - & - & - & 10 & \begin{tabular}{|c|} 
Agar dapat \\
menampung \\
beban/produk dengan \\
ukuran melebihi \\
beban/produk terbesar \\
\end{tabular} & 150 \\
\hline 6 & $\begin{array}{l}\text { Tinggi tenyangga } \\
\text { beban/produk }\end{array}$ & - & - & - & 10 & \begin{tabular}{|c|} 
Agar dapat \\
menampung \\
beban/produk dengan \\
ukuran melebihi \\
beban/produk terbesar \\
\end{tabular} & 46 \\
\hline 7 & $\begin{array}{c}\text { Tinggi tiang penyangga dan } \\
\text { tinggi hidraulik }\end{array}$ & - & - & - & 60 & \begin{tabular}{|c|} 
Agar dapat \\
menjangkau tempat \\
yang lebih tinggi pada \\
rak tingkat ke 3 \\
\end{tabular} & 600 \\
\hline 8 & Lebar pembatas & - & - & - & - & - & 30 \\
\hline 9 & Panjang pembatas & - & - & - & - & - & 100 \\
\hline 10 & Lebar alas bagian kontrol & - & - & - & - & - & 100 \\
\hline
\end{tabular}




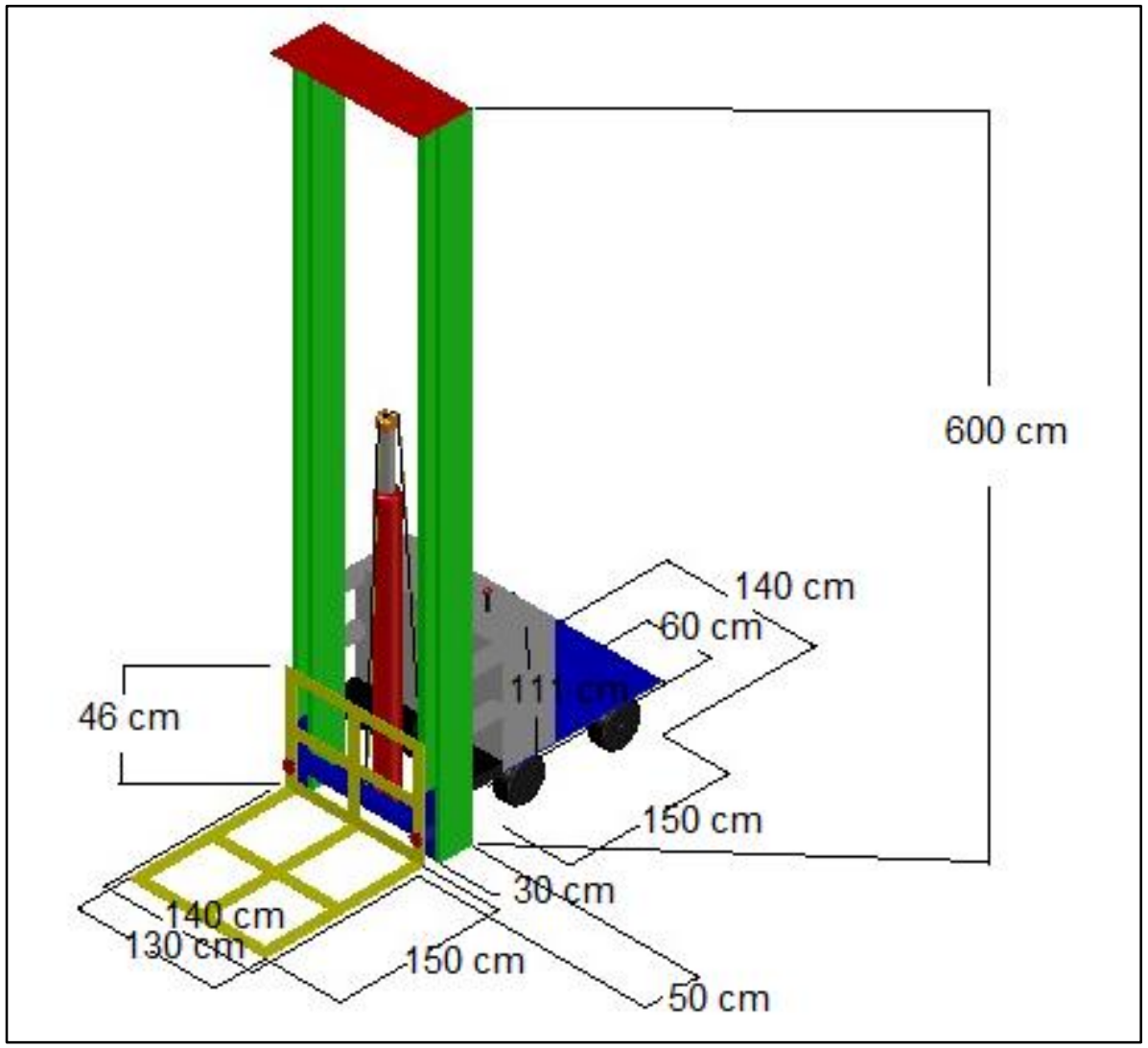

Gambar 1. Visualisasi rancangan dan pengujian risiko rancangan hand lift

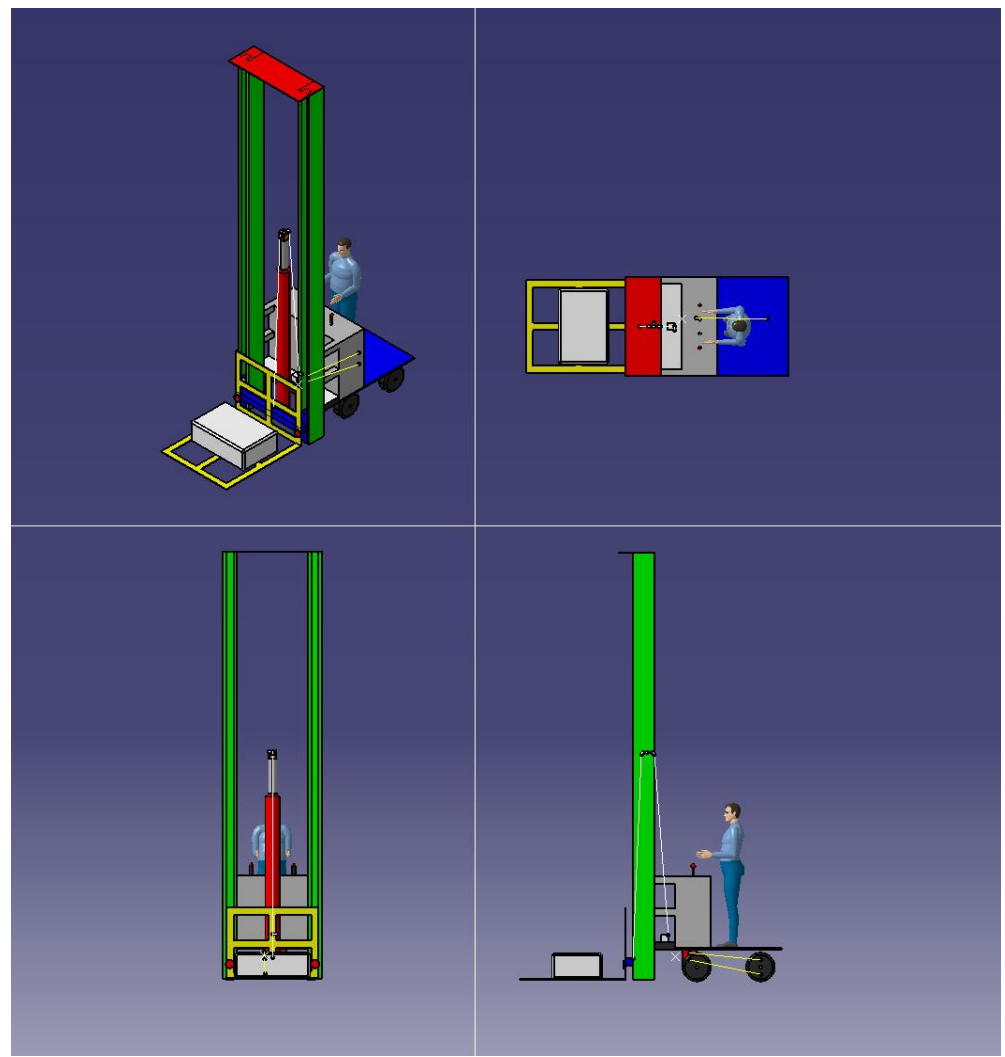

Gambar 2. Visualisasi rancangan dan pengujian risiko rancangan hand lift 


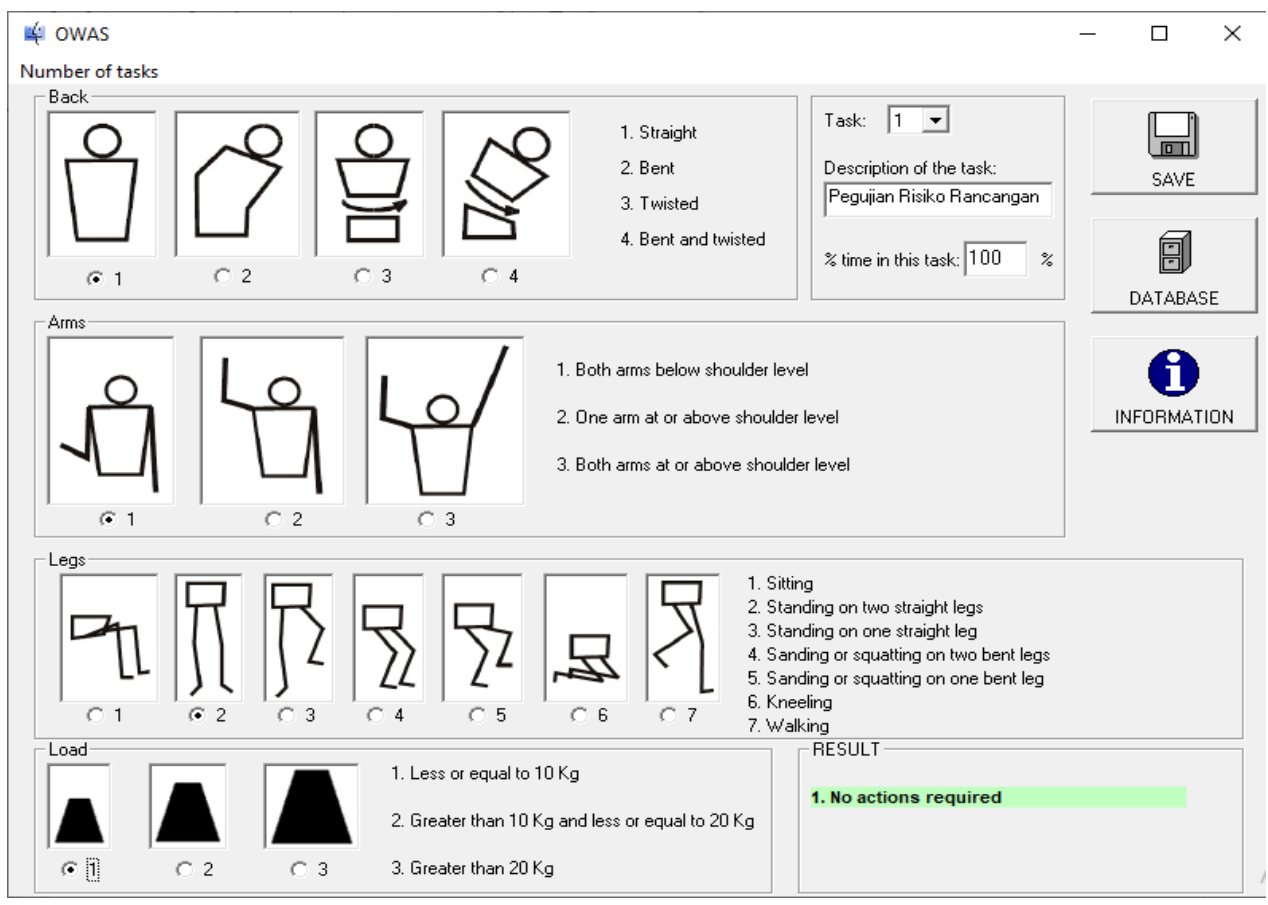

Gambar 2. Visualisasi rancangan dan pengujian risiko rancangan hand lift

Level risiko penggunaan hand lift berada pada kode 1 dimana artinya kegiatan yang dilakukan oleh operator ketika menggunakan hand lift tidak membutuhkan tindakan perbaikan tidak di perlukan. Perbandingan level risiko ketika operator memindahkan barang dengan cara manual handing dibandingkan menggunakan hand lift mengalami penurunan yang signifikan. Rata-rata operator ketika memindahkan bal produk dengan cara manual handling berada pada level risiko kode 4. Berbeda ketika operator memindahkan bal produk menggunakan hand lift, nilai level risiko menjadi kode 1 dimana tindakan perbaikan tidak diperlukan.

\section{Rancangan Biaya Pembuatan Hand Lift}

Terdapat beberapa komponen yang digunakan dalam pembuatan rancangan hand lift, antara lain plat besi, hidraulik, tombol, besi, roda, as roda, v-belt, rantai, laher (bearing), karet kontrol, as roda, aki, dan mesin penggerak. Perancangan mengenai biaya pembuatan Hand Lift lebih kurang total berada pada angka Rp 28.641.00. Sesuai dengan musyawarah dengan pihak perusahaan, dalam rangka mengimplementasikan rancangan agar di buat dan di pergunakan di warehose. PT $\mathrm{X}$ menyanggupi pembuatan Hand Lift dengan jumlah biaya yang telah di rancang oleh peneliti.

\section{Keterkaitan Penelitian dengan Ayat Al-Qur'an}

Berdasarkan keluhan yang dirasakan operator dan tingginya level risiko ketika operator manual handling memindahkan bal, maka hal ini perlu perhatikan serius. Keterkaitan antara penelitian ini dengan Al-Qur'an surat Ali-Imran ayat 159 adalah ketika mendapatkan permasalahan kita perlu bermusyawarah dengan membulatkan tekad, serta bertawakal kepada Allah untuk mencari solusi ketika menghadapi masalah dan memutuskan keputusan untuk mendapatkan hasil yang terbaik. Setiap pekerjaan hendaknya selalu diniatkan dengan tekad yang bulat, melakukan pekerjaan dengan bersungguh-sungguh, dan bertawakal kepada Allah. Diharapkan dengan dibuatnya penelitian ini dengan musyawarah dan segala masukan baik pihak perusahaan, dosen pembimbing, penguji, dan penulis dapat menyelesaikan masalah yang ada pada operator dan umumnya pada perusahaan. Perancangan fasilitas kerja di warehouse PT X yaitu hand lift diharapkan dapat meminimasi risiko kerja operator pemindahan bal atau kegiatan manual handling. 


\section{Kesimpulan}

Berdasarkan pembahasan dalam penelitian ini, peneliti menyimpulkan beberapa hasil penelitian sebagai berikut:

1. Operator pemindahan produk di warehouse mengeluhkan sakit pada beberapa bagian tubuh terutama pada bagian punggung bawah, punggung atas, dan bahu.

2. Level risiko kerja operator manual handling di warehouse berdasarkan penilaian menggunakan metode Ovako Working Analysis System (OWAS) tool software ErgoFellow untuk kegiatan mengangkat bal produk berada pada kode 3 untuk operator 1, kode 4 untuk operator 2 dan 3. Penilaian level risiko pada operator untuk aktivitas membawa/memindahkan bal produk berada pada kode 2 untuk operator 1 dan 3, kode 1 untuk operator 2. Penilaian level risiko pada operator untuk aktivitas menyimpan bal produk ke pallet berada pada kode 4 untuk semua operator semua. Penilaian level risiko pada operator untuk aktivitas menaiki tangga berada pada kode 4 untuk semua operator. Penilaian level risiko pada operator untuk aktivitas menyimpan bal produk ke rak berada pada kode 1 untuk operator 1, kode 4 untuk operator 2 dan 3.

3. Rancangan fasilitas kerja yang dibuat yaitu hand lift, dimana perancangan hand lift ini dibuat agar dapat meminimasi risiko kerja untuk semua kegiatan pemindahan bal produk atau kegiatan manual handling.

4. Perbandingan risiko kerja yang diterima oleh operator manual handling di warehouse ketika memindahkan bal produk memiliki rata-rata level risiko pada kode 4 yang artinya tindakan perbaikan diperlukan secepat mungkin dan level risiko setelah perancangan berada pada kode 1 yang artinya tindakan perbaikan tidak diperlukan.

\section{Acknowledge}

Segala puji dan syukur penulis panjatkan kepada Allah SWT atas berkat, rahmat, dan hidayahNya sehingga penulis dapat menyelesaikan Tugas Akhir dengan sesuai harapan. Tak lupa shalawat serta salam semoga tercurahkan kepada Nabi Muhammad SAW, yang telah memberikan pedoman hidup yakni Al-Qur'an dan sunnah untuk keselamatan umat dunia. Penulisan Tugas Akhir ini bertujuan untuk memenuhi salah satu syarat untuk mencapai gelar Sarjana Teknik pada Program Studi Teknik Industri Universitas Islam Bandung. Selama penulisan Tugas Akhir ini, banyak sekali bantuan dan bimbingan yang diperoleh. Oleh karena itu, ucapan terima kasih disampaikan kepada:

1. Kepada kedua Orang Tua penulis yaitu Bapak Kusyanadi, S.K.M. dan Ibu Eti Sumarti, S.S.T. yang telah memberikan dukungan baik itu moril maupun materil serta memberikan motivasi setiap saat.

2. Ibu Eri Achiraeniwati, S.T., M.M., IPM. selaku Dosen Pembimbing yang senantiasa memberikan arahan, meluangkan waktu, tenaga, dan pikiran untuk membantu membimbing menyelesaikan Tugas Akhir ini.

3. PT X, Bapak Chaka selaku Kepala Warehouse dan Operator Manual Handling Warehouse.

4. Bapak Nur Rahman As'ad, S.T., M.T., IPM. dan Ibu Yanti Sri Rejeki, S.T., M.T., IPM. selaku Kasie Laboratorium Analisis Perancangan Kerja \& Ergonomi yang telah memberikan banyak ilmu, pengalaman, dan kesempatan kepada penulis.

5. Seluruh tenaga pendidik dan administrasi Teknik Industri Universitas Islam Bandung.

6. Seluruh teman-teman Teknik Industri 2017 yang telah membentuk mental dan pribadi penulis menjadi lebih kuat hingga saat ini.

7. Tim Asisten Laboratorium APK \& Ergonomi yang telah sama-sama berjuang hingga saat ini.

8. Terkasih Indri dan rekan-rekan terdekat yaitu saudara Irvan, Rafi, Naufal, Yudio, Hafiz, Titan, Gifari, Anwar dan Aksan yang selalu memberikan dukungan secara moril kepada penulis. 


\section{Daftar Pustaka}

[1] Dahlius, A. dan Ibrahim M., 2016. Pengaruh fasilitas kerja terhadap kepuasan kerja karyawan pada PT. Bank Riau Kepri Cabang Teluk Kuantan Kabupaten Kuantan Singingi. JOM FISIP, 3(2), 1-13.

[2] Health and Safety Executive. 2016. Manual handling operations regulation 1992. Norwich: British Standards.

[3] Kementerian Tenaga Kerja, 2018. Manual Handling. Peraturan Menteri Ketenagakerjaan Republik Indonesia No. 5 Tahun 2018, 5, 1-258.

[4] NIOSH.1994. Musculoskeletal Disorders and Workplace Factors:A Critical Review of Epidemiologic Evidence for Work Related Musculoskeletal Disorders.

[5] Purnomo, H., 2017. Material manual handling. Journal of Chemical Information and Modeling, 53(9), 1689-1699.

[6] Yamane, Taro. (1967). Teknik pengambilan sampel. Jakarta: PT. Raja Grafindo Persada. 